\title{
Predictors of one-year outcomes in chronic heart failure: the portrait of a middle income country
}

Luciana Gioli-Pereira ${ }^{1 *}(\mathbb{D}$, Fabiana G. Marcondes-Braga², Sabrina Bernardez-Pereira', Fernando Bacal², Fábio Fernandes ${ }^{3}$, Alfredo J. Mansur ${ }^{3+}$, Alexandre C. Pereira ${ }^{1+}$ and José E. Krieger ${ }^{1+}$

\begin{abstract}
Background: Heart failure (HF) is a major public health problem with increasing prevalence worldwide. It is associated with high mortality and poor quality of life due to recurrent and costly hospital admissions. Several studies have been conducted to describe HF risk predictors in different races, countries and health systems. Nonetheless, understanding population-specific determinants of HF outcomes remains a great challenge. We aim to evaluate predictors of 1-year survival of individuals with systolic heart failure from the GENIUS-HF cohort.

Methods: We enrolled 700 consecutive patients with systolic heart failure from the SPA outpatient clinic of the Heart Institute, a tertiary health-center in Sao Paulo, Brazil. Inclusion criteria were age between 18 and 80 years old with heart failure diagnosis of different etiologies and left ventricular ejection fraction $\leq 50 \%$ in the previous 2 years of enrollment on the cohort. We recorded baseline demographic and clinical characteristics and followed-up patients at 6 months intervals by telephone interview. Study data were collected and data quality assurance by the Research Electronic Data Capture tools. Time to death was studied using Cox proportional hazards models adjusted for demographic, clinical and socioeconomic variables and medication use.

Results: We screened 2314 consecutive patients for eligibility and enrolled 700 participants.

The overall mortality was 6.8\% (47 patients); the composite outcome of death and hospitalization was $17.7 \%$ (123 patients) and 1\% (7 patients) have been submitted to heart transplantation after one year of enrollment. After multivariate adjustment, baseline values of blood urea nitrogen (HR 1.017; Cl 95\% 1.008-1.027; $p<0.001$ ), brain natriuretic peptide (HR 1.695; Cl 95\% 1.347-2.134; $\mathrm{p}<0.001)$ and systolic blood pressure (HR 0.982;Cl $95 \%$ 0.969-0.995; $p=0.008)$ were independently associated with death within 1 year. Kaplan Meier curves showed that ischemic patients have worse survival free of death and hospitalization compared to other etiologies.
\end{abstract}

Conclusions: High levels of BUN and BNP and low systolic blood pressure were independent predictors of one-year overall mortality in our sample.

Trial registration: Current Controlled Trials NTC02043431, retrospectively registered at in January 23, 2014. Keywords: Systolic heart failure, Outcomes, Mortality predictors

\footnotetext{
* Correspondence: lu_gioli@yahoo.com

${ }^{\dagger}$ Alfredo J. Mansur, Alexandre C. Pereira and José E. Krieger contributed equally to this work.

${ }^{1}$ Laboratory of Genetics and Molecular Cardiology, Heart Institute (InCor) of

University of São Paulo Medical School, Avenue Dr. Enéas de Carvalho,

Aguiar, 44 Cerqueira César, São Paulo, SP 05403-000, Brazil

Full list of author information is available at the end of the article
}

(c) The Author(s). 2019 Open Access This article is distributed under the terms of the Creative Commons Attribution 4.0 International License (http://creativecommons.org/licenses/by/4.0/), which permits unrestricted use, distribution, and reproduction in any medium, provided you give appropriate credit to the original author(s) and the source, provide a link to the Creative Commons license, and indicate if changes were made. The Creative Commons Public Domain Dedication waiver (http://creativecommons.org/publicdomain/zero/1.0/) applies to the data made available in this article, unless otherwise stated. 


\section{Background}

Heart failure (HF) is a major public health problem with increasing prevalence worldwide [1]. Once established, worsening heart failure is frequent and associated with significantly diminished quality of life, recurrent hospital admissions and direct impacts in healthcare costs [2]. The estimated prevalence of HF is 1 to $2 \%$ of the adult population in developed countries [3]. In Brazil, the HF prevalence is 2 million patients and its incidence is 240 , 000 new cases per year [4].

Despite the fact that most data on outcomes in patients with HF come from North America and Europe [5]; recently, several studies reported the risk factor prevalence and mortality predictors variation among races [6-8]. Brazil has the largest universal health system in the world; in addition, it is characterized by intense racial admixture, social inequalities and cultural traditions that may impact the natural history of HF. Finally, comprehensive epidemiological, clinical and therapeutic data on chronic HF are still lacking and making the definition of population strategies for disease treatment and prevention at the least difficult to forecast.

In this scenario, we have conducted the GENIUS-HF (Genetic and ElectroNic medIcal records to predict oUtcomeS in Heart Failure patients) study, a Brazilian cohort that aims to contribute with the characterization of risk predictors and the impact of multimorbidity related to chronic HF [9].

The purpose of this study was to describe baseline characteristics, one-year outcomes and predictors of mortality and hospitalization of chronic heart failure patients.

\section{Methods}

\section{The cohort}

GENIUS-HF (Genetic and ElectroNic medIcal records to predict oUtcomeS in Heart Failure patients) is an observational, prospective, single-center cohort started in 2012 and still ongoing. Invited individuals were patients with chronic systolic heart failure sequentially seen at the SPA outpatient clinic at the Heart Institute, University of São Paulo Medical School (InCor - HCFMUSP). The SPA clinic is an outpatient clinic responsible for triaging patients from primary and secondary care sites to a tertiary care site. The rationale and design for this study have been previously published [9]. Since 2012, 700 patients were included from 2314 individuals screened at the outpatient clinic due to HF symptoms (Fig. 1: Flowchart). Enrolled patients were submitted to a clinical baseline evaluation, complementary exams (echocardiography, cardiograph impedance) and biochemical tests, which included blood, urine and biobanking samples for future analysis. After enrollment, patients would be taken care at different units of the public medical system and study investigators did not influence any of the medical decisions involving participants. Follow-up was made thru phone interview every six-months.

\section{Ethical aspects}

The study protocol was approved by the Ethics Committee for Medical Research on Human Beings of the Clinical Hospital from University of São Paulo Medical School (Protocol number SDC 2368/03/162). Signed informed consent was obtained from all participants. This study was retrospectively registered at clinicaltrials.gov (NTC02043431) in January 23, 2014.

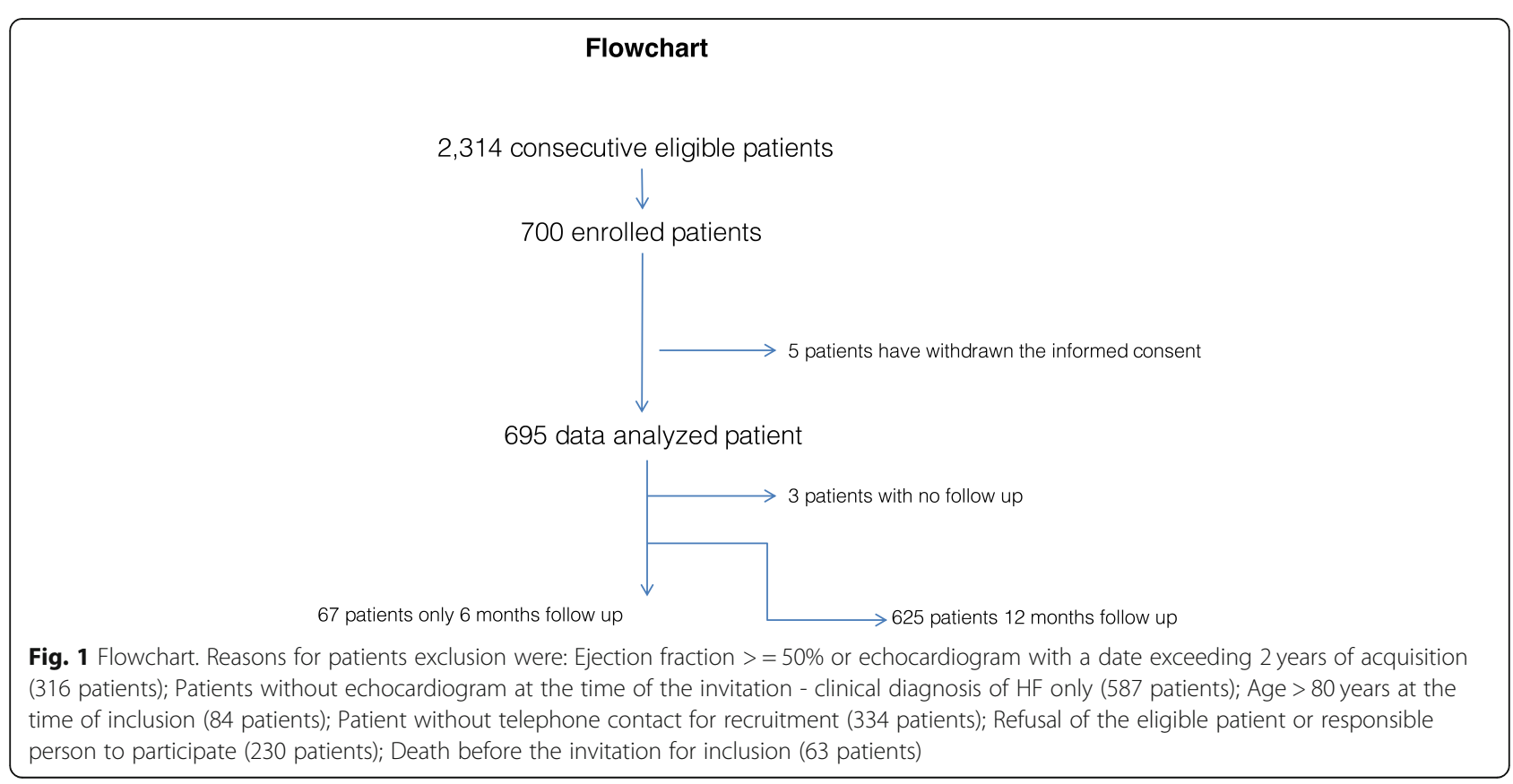




\section{Eligibility criteria}

Patients between 18 and 80 years old and with systolic heart failure diagnosis from different etiologies were eligible for enrollment in the cohort. The left ventricular ejection fraction $\leq 50 \%$ was confirmed on twodimensional transthoracic Doppler echocardiography performed in the past 2 years before enrollment. The diagnosis of heart failure was made according to previously published criteria [10]. To define the appropriate etiology of cardiomyopathy, the authors followed previous guidelines $[11,12]$. Patients with impaired cognition due to advanced dementia or severe psychiatric disorder, without telephone access or that refused to participate in follow-up procedures were not eligible.

\section{Studied variables}

Data collection included demographic variables (sex, ethnicity, age) duration of symptoms, etiology of heart failure, comorbidities, smoking status, body mass index, heart rate, blood pressure, cardiac rhythm, and cardiac dimensions, left ventricle ejection fraction, medication use and clinical outcomes.

\section{Outcomes}

Patients included have been submitted to telephone follow-up in 6 and 12-months to assess cardiovascular outcomes: all-cause mortality, hospitalization and heart transplantation. Regarding the 67 patients that had only the first telephone contact, we consider the events occurred in this period of follow up. All events were adjudicated by study investigators.

\section{Statistical analysis}

Means and SD were calculated for continuous variables, counts and percentages for categorical.

variables, and median (IQR) for BNP due to nonnormality. We performed logarithmic.

transformation of BNP in order to normalize the sample data for analysis. Baseline characteristics were compared using One-way ANOVA followed by Dunnet for continuous variables and Chi-square test for categorical variables. The prognostic value was tested by univariate and multivariate Cox proportional hazard analysis. The multivariate analysis was constructed with the significant variables in the bivariate model. A value of $p<0.05$ was considered statistically significant for all comparisons. These analyses were performed using a statistical software package e (SPSS ver. 20.0, IBM, Armonk, NY, USA).

\section{Results}

Since 2012 we screened 2314 consecutive patients for eligibility and enrolled 700 participants. This paper describes the prognosis value of clinical baseline and laboratorial characteristics of the sample.
Five individuals have withdrawn the informed consent and were excluded from the study. Among 695 participants, $3(0.4 \%)$ individuals did not respond to any follow-up contact and 67 (9.6\%) have only the 6-month contact (Fig. 1, flowchart).

The overall one-year mortality was $6.8 \%$ (47 patients) and the composite outcome of death or hospitalization was $17.7 \%$ (123 patients). Seven patients (1\%) have been submitted to heart transplantation during one year of enrollment.

The baseline characteristics of the individuals (Table 1) showed a mean age of 55.4 years old and male gender predominance $(67.6 \%)$ as well as selfreferred mixed race (49.6\%). The main comorbidities were dyslipidemias (66.5\%) followed by hypertension (64.5\%), diabetes (29.5\%) and chronic kidney disease (26.9\%). In this sample, 9.2\% were previous or current smokers.

Regarding heart failure etiology distribution, we observed a predominance of hypertensive (26.0\%), ischemic (21.9\%) and chagasic (17.0\%) forms of cardiomyopathy. Most of the included individuals were in NYHA class I/ II $(81 \%)$ at enrollment.

Mean BMI (body mass index) was $27.9 \mathrm{~kg} / \mathrm{m} 2$. Eighty six percent of the patients reported dyspnea as a symptom and jugular venous distension was the most observed clinical sign at examination (36\% of the patients). Median BNP (brain natriuretic peptide) was $149 \mathrm{pg} / \mathrm{mL}$ (interquartile range: 54-355). Regarding medication, 96.8\% of patients were in use of a beta-blocker; $91.1 \%$ used ACEi or ARB medication and $90.8 \%$ of the patients were in use of some diuretic at baseline.

Table 2 presents results for the Cox proportional hazards regression model estimated in the cohort using all pre-specified clinical and demographic characteristics. After multivariate adjustment, BUN (hazard ratio [HR] 1.017; 95\% CI 1.008-1.027), Log BNP (hazard ratio [HR] 1.695; 95\% CI 1.347-2.1134) and systolic blood pressure (hazard ratio [HR] 0.982; 95\% CI $0.969-0.995)$ were independently associated with death within 1 year.

We have also analyzed the composite endpoint of death and hospitalization in 1 year (Table 3). After multivariate adjustment, BUN (hazard ratio [HR] 1.008; 95\% CI 1.001-1.015), Log BNP (hazard ratio [HR] 1.338; 95\% CI 1.158-1.545), high sensitive troponin (hazard ratio [HR] 8.801; 95\% CI 1.824-42.466) and age (hazard ratio [HR] 1.026; 95\% CI 1.010-1.043) were associated with death and hospitalization within 1 year.

In Fig. 2, Kaplan Meier curves compared all etiologies. Ischemic patients had worse survival free of death and hospitalization followed by chagasic and idiopathic compared to other etiologies. 
Table 1 Baseline demographic and clinical characteristics

\begin{tabular}{|c|c|}
\hline Variable & Total $(n=695$ \\
\hline Age (years) & $55.4+12.2$ \\
\hline Gender (Male) n(\%) & $470(67.6)$ \\
\hline \multicolumn{2}{|l|}{ Race n(\%) } \\
\hline Asian & $7(1.0)$ \\
\hline Black & $107(15.4)$ \\
\hline Mixed & $345(49.6)$ \\
\hline White & $236(34.0)$ \\
\hline Hypertension n(\%) & $448(64.5)$ \\
\hline Diabetes n(\%) & $205(29.5)$ \\
\hline Dyslipidemias n(\%) & $462(66.5)$ \\
\hline Smoking n(\%) & $64(9.2)$ \\
\hline Chronic Renal Failure n(\%) & $187(26.9)$ \\
\hline COPD n(\%) & $49(0.07)$ \\
\hline CABG n(\%) & $34(0.04)$ \\
\hline $\mathrm{PCl}$ n(\%) & $50(0.07)$ \\
\hline HIV n(\%) & $2(0.003)$ \\
\hline \multicolumn{2}{|l|}{ Heart Failure Class n(\%) } \\
\hline NYHA I & $130(18.7)$ \\
\hline NYHA $\|$ & $433(62.3)$ \\
\hline NYHA III & $127(18.3)$ \\
\hline NYHA IV & $5(0.7)$ \\
\hline Ejection Fraction (\%) & $32.0+8.6$ \\
\hline LVDD n(\%) & $64.1+8.3$ \\
\hline \multicolumn{2}{|l|}{ Heart failure etiology n(\%) } \\
\hline hypertensive & $181(26.0)$ \\
\hline ischemic & $152(21.9)$ \\
\hline chagasic & $118(17.0)$ \\
\hline idiopathic & $108(19.6)$ \\
\hline other & $136(8.6)$ \\
\hline Weight (Kg) & $75.8+19.1$ \\
\hline Body mass index (kg/m2) & $27.9+6.0$ \\
\hline Heart rate (bpm) & $71.2+14.3$ \\
\hline Systolic blood pressure $(\mathrm{mmHg})$ & $123.5+23.8$ \\
\hline Diastolic blood pressure (mmHg) & $76.2+14.6$ \\
\hline Dyspnea n(\%) & $599(86.2)$ \\
\hline Orthopnea n(\%) & $263(37.8)$ \\
\hline Paroxysmal nocturnal dyspnea n(\%) & $150(21,6)$ \\
\hline Jugular venous distension n(\%) & $250(36.0)$ \\
\hline Pulmonary rales n(\%) & $52(7.5)$ \\
\hline Peripheral edema n(\%) & $127(18.3)$ \\
\hline Third heart sound n(\%) & $50(7.2)$ \\
\hline Hepatojugular reflux n(\%) & $71(10.2)$ \\
\hline Capillary filling time (3-5 s) n(\%) & $19(2.7)$ \\
\hline Ascitis n(\%) & $18(2.6)$ \\
\hline
\end{tabular}

Table 1 Baseline demographic and clinical characteristics (Continued)

\begin{tabular}{ll}
\hline Variable & Total $(n=695)$ \\
\hline Hepatomegaly $\mathrm{n}(\%)$ & $79(11.4)$ \\
Creatinine $(\mathrm{mg} / \mathrm{dL})$ & $1.27+0.77$ \\
Blood urea nitrogen $(\mathrm{mg} / \mathrm{dL})$ & $49.3+23.7$ \\
CKD-EPI ( $\mu \mathrm{mol} / \mathrm{L})$ & $68.2+22.7$ \\
Sodium $(\mathrm{mg} / \mathrm{dL})$ & $139.3+2.72$ \\
Potassium (mg/dL) & $4.8+0.6$ \\
Hemoglobin (mg/dL) & $13.9+1.7$ \\
Hematocrit (\%) & $43.0+5.2$ \\
Blood glucose fasting (mg/dL) & $113.6+51.2$ \\
Glycated hemoglobin (\%) & $6.3+0.7$ \\
High sensitive troponin (ng/dL) & $0.040+0.062$ \\
BNP (pg/mL) & $149(54-355)$ \\
Medication in use $n(\%)$ & \\
Beta blocker & $673(96.8)$ \\
ACE inhibitor & $427(61.4)$ \\
ARB & $207(30.0)$ \\
Nitrate & $98(14.1)$ \\
Hydralazine & $116(16.7)$ \\
Diuretic & $631(90.8)$ \\
Digital & $165(23.7)$ \\
Lipid lowering & $332(47.8)$ \\
\hline
\end{tabular}

Continuous variables are expressed as mean \pm SD

Categorical variables are presented as absolute number and percentage [n (\%)]

BNP was expressed as median (interquartile range) due to non-normality COPD Chronic Obstructive Pulmonary Disease, CABG Coronary Artery Bypass Grafting, $P C l$ Percutaneous Coronary Intervention, HIV Human Immunodeficiency Virus, NYHA New York Heart Association, LVDD left ventricular end diastolic dimension, CKD-EPI Chronic Disease Epidemiology Collaboration, $B N P$ brain natriuretic peptide, $A C E i$ angiotensin converting enzyme inhibitor, $A R B$ angiotensin II receptor blocker

\section{Discussion}

We observed an overall mortality of $6.8 \%$ and a composite outcome of death and hospitalization of $17.7 \%$ in 1year of follow-up. It is known that the HF mortality increases with the follow-up time and can reach a median of $40 \%$ in 2.5 years [13]. Our results are in agreement with previous reports. For instance, Maggioni et al. observed all-cause mortality rate at 1 year of $7.2 \%$ in chronic stable HF in a pilot study [14]. In addition, the continuation of this study showed all-cause 1-year mortality rate of $6.4 \%$ and combined endpoint of mortality or HF hospitalization within 1 year of $14.5 \%$ [15].

In our cohort, the variables associated with allcause mortality at 1 year were elevated BUN or log BNP and lower SBP. On the other hand, considering the composite endpoint death and hospitalization, the predictors were age, high sensitive troponin, BNP and BUN. Previous studies have shown a variety of risk 
Table 2 Variables associated with all-cause mortality at 1 year

\begin{tabular}{|c|c|c|c|c|c|c|}
\hline \multirow[b]{2}{*}{ Variables } & \multicolumn{3}{|c|}{$\underline{\text { Univariate analysis }}$} & \multicolumn{3}{|c|}{ Multivariate analysis } \\
\hline & $\mathrm{HR}$ & $95 \% \mathrm{Cl}$ & $p$ & $\mathrm{HR}$ & $95 \% \mathrm{Cl}$ & $p$ \\
\hline Age & 1.026 & $1.001-1.051$ & 0.360 & & & \\
\hline Gender & 0.884 & $0.642-1.216$ & 0.448 & & & \\
\hline Ejection fraction & 0.951 & $0.917-0.987$ & 0.007 & 1.007 & $0.967-1.049$ & 0.736 \\
\hline Hemoglobin & 0.846 & $0.721-0.993$ & 0.041 & & & \\
\hline Sodium & 0.956 & $0.859-1.064$ & 0.411 & & & \\
\hline BUN & 1.024 & $1.017-1.032$ & $<0.001$ & 1.017 & $1.008-1.027$ & $<0.001$ \\
\hline Log BNP & 2.074 & $1.664-2.585$ & $<0.001$ & 1.695 & $1.347-2.134$ & $<0.001$ \\
\hline Systolic blood pressure & 0.972 & $0.958-0.986$ & $<0.001$ & 0.982 & $0.969-0.995$ & 0.008 \\
\hline High sensitive troponin & 22.765 & $3.155-164.252$ & 0.002 & 16.717 & $0.960-291.250$ & 0.053 \\
\hline
\end{tabular}

$B U N$ blood urea nitrogen, Log BNP brain natriuretic peptide logarithmic

Variables which univariate analysis resulted in $p<0.04$ were included in a multivariate analysis

predictors $[13,16,17]$ and between then, it is common to find creatinine as representative of renal function and systolic blood pressure. However, although BNP is markedly related to prognosis $[18,19]$ it is not present in the best-known risk models [13, 16]. Due to the fact that studies in chronic heart failure are scarce in the Brazilian population, there are no known critical variables in our population, except in acute patients as in the BREATHE Registry [20].

The majority of included individuals were in NYHA class I/II (81\%) denoting the stable-outpatient character population. Besides, the use of beta-blocker $(96.8 \%)$ and ACEi or ARB (91\%) was high. These facts refer to the good clinical care of the cohort, certainly influencing outcomes.

There was a predominance of hypertensive (26.0\%) and ischemic (21.9\%) etiologies in our sample, on the other hand, the number of chagasic patients was also important (17.0\%). Most studies describe ischemic as the main etiology found in the HF population, however, it depends on study design and ascertainment approaches [5]. Nonetheless, in our population, Chagas disease is still a major concern. In Brazil, there are endemic areas of Chagas' disease such as the Midwest region [21] and migration movements can explain this relative high prevalence. Recently, Nadruz et cols evaluated the population attributable risk (PAR) of Chagas cardiomyopathy for 2-year mortality among patients with HF enrolled at years 2002-2004 (era 1) and 20122014 (era 2). The era 2 population is part of our cohort and the results found were that although the absolute death rates decreased over time in the Chagas cardiomyopathy and non-Chagas cardiomyopathies groups, the PAR of Chagas cardiomyopathy for mortality increased among patients with HF. Therefore, the current knowledge indicate that of all etiologies, Chagasic HF has the worst prognosis [22]. In addition, BernardezPereira et al. analyzed the association between genetic ancestry, self-declared race and hemodynamic parameters in the GENIUS-HF cohort and observed a predominance of European ancestry in the entire study population [23].Taken together, these facts make our cohort sui generis and suggest care in the use of risk prediction models from other populations.

Table 3 Variables associated with hospitalization and all-cause mortality at 1 year

\begin{tabular}{|c|c|c|c|c|c|c|}
\hline \multirow[b]{2}{*}{ Variables } & \multicolumn{3}{|c|}{ Univariate analysis } & \multicolumn{3}{|c|}{ Multivariate analysis } \\
\hline & $\overline{H R}$ & $95 \% \mathrm{Cl}$ & $\mathrm{p}$ & $\overline{H R}$ & $95 \% \mathrm{Cl}$ & $\mathrm{p}$ \\
\hline Age & 1.036 & $1.020-1.053$ & $<0.001$ & 1.026 & $1.010-1.043$ & 0.001 \\
\hline Gender & 1.004 & $0.688-1.464$ & 0.985 & & & \\
\hline Ejection fraction & 0.975 & $0.954-0.996$ & 0.020 & 0.991 & $0.967-1.015$ & 0.443 \\
\hline Hemoglobin & 0.848 & $0.767-0.936$ & 0.001 & 0.917 & $0.825-1.019$ & 0.107 \\
\hline Sodium & 0.935 & $0.874-1.001$ & 0.055 & & & \\
\hline BUN & 1.017 & $1.011-1.022$ & $<0.001$ & 1.008 & $1.001-1.015$ & 0.019 \\
\hline Log BNP & 1.547 & $1.359-1.761$ & $<0.001$ & 1.338 & $1.158-1.545$ & $<0.001$ \\
\hline Systolic blood pressure & 0.991 & $0.983-0.999$ & 0.024 & 0.994 & $0.986-1.002$ & 0.129 \\
\hline High sensitive troponin & 16.398 & $4.368-61.562$ & $<0.001$ & 8.801 & $1.824-42.466$ & 0.007 \\
\hline
\end{tabular}

BUN blood urea nitrogen, Log BNP brain natriuretic peptide logarithmic

Variables which univariate analysis resulted in $\mathrm{p}<0.04$ were included in a multivariate analysis 


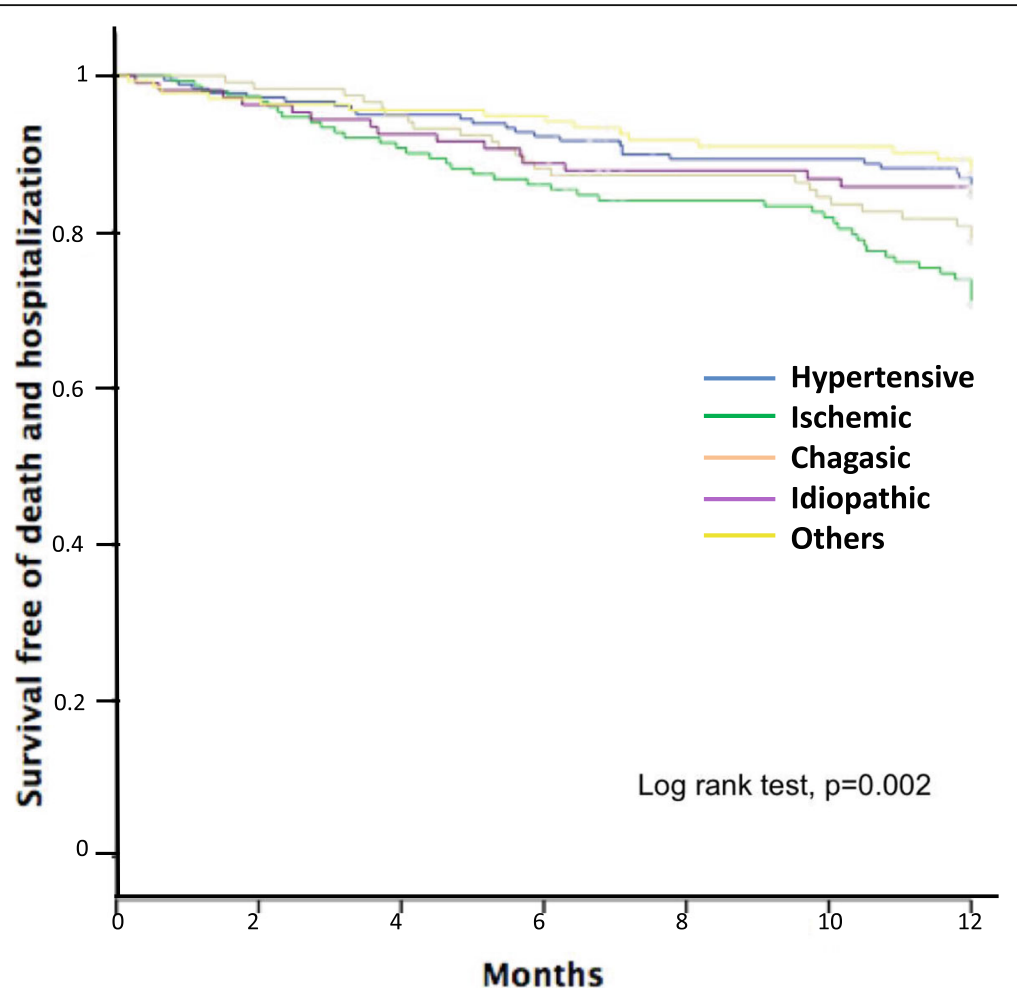

Fig. 2 Death and hospitalization for all heart failure etiologies. Shows Kaplan Meier curves for all etiologies with death and hospitalization in 12 months

The SEATTLE heart failure model was an example of a web-based calculator that estimates 1,2 and 3-year survival using clinical and pharmacological data easily obtained, but could need calibration in different ethnic populations [16]. Regardless, many publications on HF risk scores in Europe, North America [13, 16, 17] and nowadays-in Asian populations [6-8], there is a shortage of studies in the Brazilian population.

We found that patients with ischemic etiology have worse survival free of death and hospitalization in 12 months compared to others etiologies. This is a common observation to many reports and also supports prior community-based epidemiological studies that reported greater risks of coronary heart disease-related deaths [24].

\section{Limitations}

This study was specifically designed to study predictors of clinical deterioration in patients with reduced systolic fraction. For this reason we did not perform a subgroup analysis about preserved and mid range fraction patients.

This was a single-center study and, thus, our results might not be applicable to other populations. Nevertheless, the Heart Institute is a nation-wide referral center and our enrolled sample has individuals from different regions of the country.

\section{Conclusions}

High levels of BUN and BNP and low systolic blood pressure were independent predictors of one-year overall mortality in our population. Considering the composite endpoint death and hospitalization, independent predictors were age, high sensitive troponin, BNP and BUN.

\section{Abbreviations}

ACE: Angiotensin converting enzyme; ACEi: Angiotensin converting enzyme inhibitor; ARB: Angiotensin II receptor blocker; BMI: Body mass index; BNP: Brain natriuretic peptide; BUN: Blood urea nitrogen; CABG: Coronary artery bypass grafting; CKP-EPI: Chronic disease epidemiology collaboration; COPD: Chronic obstructive pulmonary disease; HF: Heart failure; HIV: Human immunodeficiency virus; LVDD: Left ventricular end diastolic dimension; NYHA: New York heart association; PCl: Percutaneous coronary intervention; SBP: Systolic blood pressure

\section{Acknowledgements}

We thank the Laboratory of Genetics and Molecular Cardiology staff for the technical support.

\section{Authors' contributions}

LGP performed the acquisition of data, drafted the manuscript. FGMB performed the acquisition of data, helped to draft the manuscript. SBP performed the acquisition of data, helped to draft the manuscript. FB helped in the patient's recruitment and revised the manuscript. FF helped in the patient's recruitment and revised the manuscript. AJM participated in the study design and coordinated patient's recruitment. ACP conceived of the study, and participated in its design and coordination and helped to draft the manuscript. JEK conceived the study, and participated in its design and manuscript critical revision. All authors read and approved the final manuscript. 


\section{Funding}

Samaritan Hospital of São Paulo and Brazilian Ministry of Health - Programa de Apoio ao Desenvolvimento Institucional do Sistema Único de Saúde (PROADI-SUS). The funding body had contributed with financial support to this work but not in the design of the study and collection, analysis, and interpretation of data or in writing the manuscript.

\section{Availability of data and materials}

The datasets analyzed during the current study are available from the corresponding author on reasonable request. They were collected and managed using REDCap electronic data capture tools hosted at the Clinical Hospital from University of São Paulo Medical School.

\section{Ethics approval and consent to participate}

The study protocol had been performed in accordance with the Declaration of Helsinki and was approved by the Ethics Committee for Medical Research on Human Beings of the Clinical Hospital from University of São Paulo Medical School (Protocol number SDC 2368/03/162).

Signed informed consent was obtained from all participants.

This study was retrospectively registered at clinicaltrials.gov (NTC02043431) in January 23, 2014.

\section{Consent for publication}

Not applicable. This manuscript does not contain any detail, images, or videos relating to an individual person.

\section{Competing interests}

The authors declare that they have no competing interests.

\section{Author details}

'Laboratory of Genetics and Molecular Cardiology, Heart Institute (InCor) of University of São Paulo Medical School, Avenue Dr. Enéas de Carvalho, Aguiar, 44 Cerqueira César, São Paulo, SP 05403-000, Brazil. ${ }^{2}$ Heart Transplant Department, Heart Institute (InCor) of University of São Paulo Medical School, São Paulo, Brazil. ${ }^{3}$ Heart Institute (InCor) of University of São Paulo Medical School, São Paulo, Brazil.

\section{Received: 30 May 2019 Accepted: 18 October 2019}

Published online: 09 November 2019

\section{References}

1. Ambrosy AP, Fonarow GC, Butler J, Chioncel O, Greene SJ, Vaduganathan M, et al. The global health and economic burden of hospitalizations for heart failure: lessons learned from hospitalized heart failure registries. J Am Coll Cardiol. 2014;63(12):1123-33.

2. Ponikowski P, Voors AA, Anker SD, Bueno H, Cleland JG, Coats AJ, et al. 2016 ESC guidelines for the diagnosis and treatment of acute and chronic heart failure: the task force for the diagnosis and treatment of acute and chronic heart failure of the European Society of Cardiology (ESC)developed with the special contribution of the heart failure association (HFA) of the ESC. Eur Heart J. 2016;37(27):2129-200.

3. Mosterd A, Hoes AW. Clinical epidemiology of heart failure. Heart. 2007; 93(9):1137-46.

4. Nogueira PR, Rassi S, Correa Kde S. Epidemiological, clinical e therapeutic profile of heart failure in a tertiary hospital. Arq Bras Cardiol. 2010;95(3):392-8.

5. Roger VL. Epidemiology of heart failure. Circ Res. 2013;113(6):646-59.

6. Echouffo-Tcheugui JB, Greene SJ, Papadimitriou L, Zannad F, Yancy CW, Gheorghiade $\mathrm{M}$, et al. Population risk prediction models for incident heart failure: a systematic review. Circ Heart Fail. 2015;8(3):438-47.

7. Dokainish H, Teo K, Zhu J, Roy A, AlHabib KF, ElSayed A, et al. Global mortality variations in patients with heart failure: results from the international congestive heart failure (INTER-CHF) prospective cohort study. Lancet Glob Health. 2017:5(7):e665-e72.

8. Leong KT, Wong LY, Aung KC, Macdonald M, Cao Y, Lee S, et al. Risk stratification model for 30-day heart failure readmission in a multiethnic south east Asian community. Am J Cardiol. 2017;119(9):1428-32.

9. Gioli-Pereira L, Bernardez-Pereira S, Goulart Marcondes-Braga F, Rocha Spina JM, Muniz Miranda da Silva R, Evangelista Ferreira N, et al. Genetic and ElectroNic medlcal records to predict oUtcomes in heart failure patients (GENIUS-HF) - design and rationale. BMC Cardiovasc Disord. 2014;14:32.
10. McKee PA, Castelli WP, McNamara PM, Kannel WB. The natural history of congestive heart failure: the Framingham study. N Engl J Med. 1971;285(26): 1441-6.

11. Bocchi EA, Marcondes-Braga FG, Bacal F, Ferraz AS, Albuquerque D, Rodrigues Dde A, et al. Updating of the Brazilian guideline for chronic heart failure - 2012. Arq Bras Cardiol. 2012;98(1 Suppl 1):1-33.

12. Ponikowski P, Voors AA, Anker SD, Bueno H, Cleland JG, Coats AJ, et al. 2016 ESC Guidelines for the diagnosis and treatment of acute and chronic heart failure: The Task Force for the diagnosis and treatment of acute and chronic heart failure of the European Society of Cardiology (ESC). Developed with the special contribution of the Heart Failure Association (HFA) of the ESC. Eur J Heart Fail. 2016;18(8):891-975.

13. Pocock SJ, Ariti CA, McMurray JJ, Maggioni A, Kober L, Squire IB, et al. Predicting survival in heart failure: a risk score based on 39372 patients from 30 studies. Eur Heart J. 2013:34(19):1404-13.

14. Maggioni AP, Dahlstrom U, Filippatos G, Chioncel O, Crespo Leiro M, Drozdz J, et al. EURObservational research Programme: regional differences and 1-year follow-up results of the heart failure pilot survey (ESC-HF pilot). Eur J Heart Fail. 2013;15(7):808-17.

15. Crespo-Leiro MG, Anker SD, Maggioni AP, Coats AJ, Filippatos G, Ruschitzka F, et al. European Society of Cardiology Heart Failure Long-Term Registry (ESC-HF-LT): 1-year follow-up outcomes and differences across regions. Eur J Heart Fail. 2016;18(6):613-25

16. Levy WC, Mozaffarian D, Linker DT, Sutradhar SC, Anker SD, Cropp AB, et al. The Seattle heart failure model: prediction of survival in heart failure. Circulation. 2006:113(11):1424-33.

17. Fonarow GC, Adams KF Jr, Abraham WT, Yancy CW, Boscardin WJ. Risk stratification for in-hospital mortality in acutely decompensated heart failure: classification and regression tree analysis. JAMA. 2005;293(5):572-80.

18. Pfister R, Diedrichs H, Schiedermair A, Rosenkranz S, Hellmich M, Erdmann E, et al. Prognostic impact of NT-proBNP and renal function in comparison to contemporary multi-marker risk scores in heart failure patients. Eur J Heart Fail. 2008;10(3):315-20.

19. Wedel H, McMurray JJ, Lindberg M, Wikstrand J, Cleland JG, Cornel JH, et al. Predictors of fatal and non-fatal outcomes in the controlled Rosuvastatin multinational trial in heart failure (CORONA): incremental value of apolipoprotein A-1, high-sensitivity C-reactive peptide and N-terminal pro Btype natriuretic peptide. Eur J Heart Fail. 2009;11(3):281-91.

20. Albuquerque DC, Neto JD, Bacal F, Rohde LE, Bernardez-Pereira S, Berwanger O, Almeida DR, et al. I Brazilian registry of heart failure - clinical aspects, care quality and hospitalization outcomes. Arq Bras Cardiol. 2015; 104(6):433-42.

21. Bocchi EA, Bestetti RB, Scanavacca MI, Cunha Neto E, Issa VS. Chronic Chagas heart disease management: from etiology to cardiomyopathy treatment. J Am Coll Cardiol. 2017;70(12):1510-24.

22. Nadruz W Jr, Gioli-Pereira L, Bernardez-Pereira S, Marcondes-Braga FG, Fernandes-Silva MM, Silvestre OM, et al. Temporal trends in the contribution of Chagas cardiomyopathy to mortality among patients with heart failure. Heart. 2018;104(18):1522-8.

23. Bernardez-Pereira S, Gioli-Pereira L, Marcondes-Braga FG, Santos PC, Spina JM, Horimoto AR, et al. Genomic ancestry as a predictor of haemodynamic profile in heart failure. Open Heart. 2016;3(2):e000434.

24. Chun S, Tu JV, Wijeysundera HC, Austin PC, Wang X, Levy D, et al. Lifetime analysis of hospitalizations and survival of patients newly admitted with heart failure. Circ Heart Fail. 2012;5(4):414-21.

\section{Publisher's Note}

Springer Nature remains neutral with regard to jurisdictional claims in published maps and institutional affiliations. 